\title{
HYDROGEN-SENSITIZED FINE-GRAIN QUASI-T ASTRONOMICAL PLATES
}

\author{
D.K. MIKHAILOV ${ }^{1}$ and P.V. SHEGLOV ${ }^{2}$ \\ ${ }^{1} 2$ Mendelear Sq., Pereyaslavl-Zalessky, Yaroslavl Region, 152140, Russia \\ ${ }^{2}$ Sternberg Astronomical Institute, Moscow 117234, Russia
}

As we know, the first report on photographic plate hydrogen hypersensitisation (hypering) is dated 1871 (U.S. Patent No. 113327, April 4 1871, see Janusonis et al. 1978). A new interest in the topic appeared in the 1930s, after the work of Robert Kozlowsky at Agfa Wolfen. Kozlowsky was the inventor of gold sensitization. In the 1950 s in Russia the action of hydrogen on thick nuclear emulsions was also studied (Tschernyavsky et al. 1962). Strong fogging, especially at increased temperatures, was observed.

Another period of intense interest in hydrogen hypering was connected with the work of Babcock, James and Lewis at Eastman Kodak. In 1974, they found a marked lowering of reciprocity failure after hydrogen hypering, an effect important for astronomy. In 1975 the use of warm hydrogen was suggested. It must be noted that hydrogen hypering acts in an independent way from other sensitisers, so it can produce ultimate efficiency.

It appears that hydrogen acts as a slow chemical reducing agent, aiding the formation of an AgAg quasimolecule with hole-accepting capability on the faces of the silver halide crystals. It preferentially locates on the cubic faces of the crystal. Chemical sensitizers such as gold and thiosulphate react better on the octahedral faces so their action is independent.

A photochemical reaction, the mechanism for which was suggested by James, allows the two electrons given by the $\mathrm{AgAg}$ quasimolecule to react with two interstitial $\mathrm{Ag}^{+}$ions, forming a stable $\mathrm{Ag}_{2}$ subcentre, growing to a latent image subcentre of at least four silver atoms.

Good hypering was urgently needed to use the three new $1 \mathrm{~m}$ Zeiss Jena reflectors put in operation in good dark sites in Middle Asia. Having a rather slow focal ratio of F/13.5 these Ritchey-Chretien telescopes cannot reach the sky background with unhypered 103a-O or ZU21.

At that time it was found that ZU21 shows no increase of sensitivity when hypered at room temperature. Warm hydrogen hypering was tried in a double-walled tank with circulating water. A thermistor near the plates was not used, only the temperature of water being measured. The plates were put into the tank, which was pumped out to $2 \times 10^{-2} \mathrm{~mm} \mathrm{Hg}$, then the heating was turned on and the tank filled with hydrogen. The typical time of hypering is 45 mins at $46 \mathrm{C}$. The temperature must be adjusted so as not to give a strong chemical fog. After hypering the plates cool in air.

A communication from the chemistry department of the Moscow University proposed a very good method of storing hydrogen. This is probably a German invention - a powder of a special alloy having a strong hydrogen absorbing capability. A two litre cylinder of this alloy absorbs 
about 200 litres of hydrogen at 2 - 3 atm. pressure. The desorbed hydrogen is cleaner than that which has been absorbed. Such accumulators have been used at Sternberg for several years.

In the late 1980s the hypering tank and the technology were transferred to the Sternberg Institute, where they proved to be reliable. At this time it occurred to us to develop an emulsion with ' $T$ ' (tabular) crystals and coat it on glass ourselves. The emulsion would be slow, but designed for use with hypering (Fig. 1).

The aspect ratio of the new emulsion crystals is $3-6: 1$, and the developed crystals have

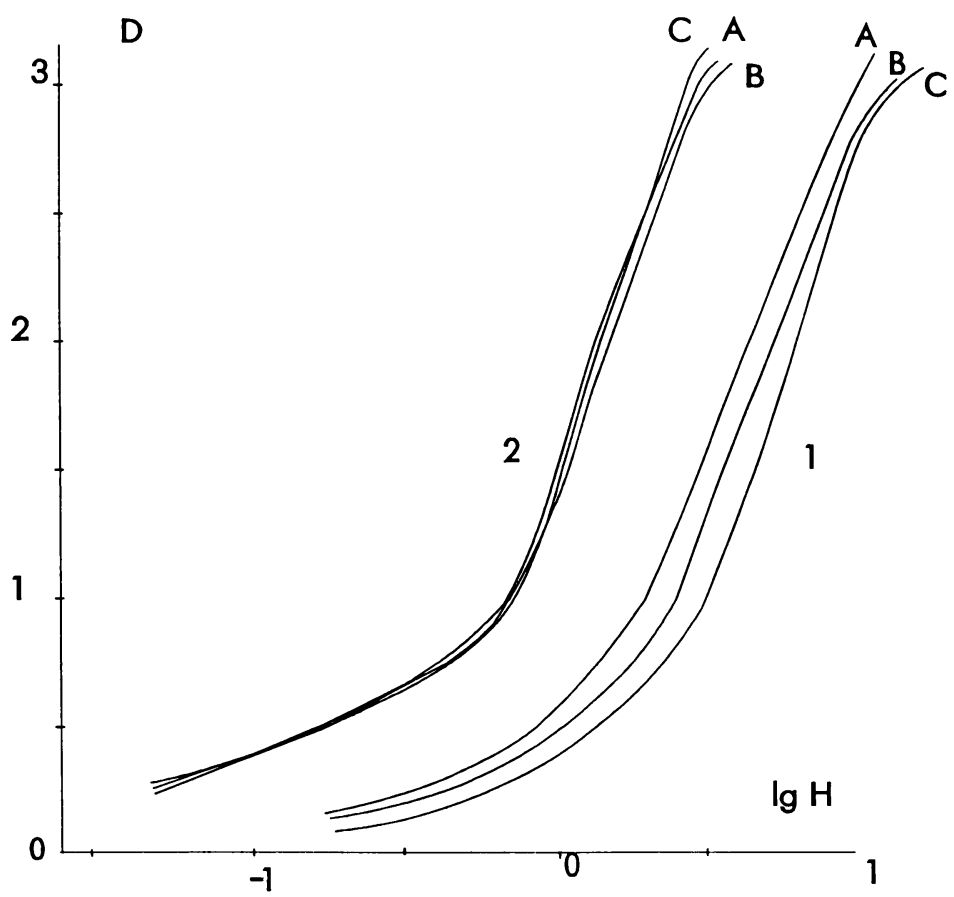

Figure 1.

dimensions $0.95-1.25 \mu \mathrm{m}, 70 \%$ falling in the limits $1.08 \pm 0.08 \mu \mathrm{m}$. The new emulsion, NT-1A, is of the non-dye-sensitised silver bromide type, with an addition of $3 \%$ silver iodide. Before hypering it can be stored at room temperature for at least one year (Fig. 2). Hypered plates can be stored between +4 and $+8 \mathrm{C}$ for about one month. After hypering the new emulsion has the sensitivity of unhypered 103a-O or ZU21, but the graininess is much better (Fig. 3).

The first astronomical tests of NT-1A have been published in the ESO Messenger, March 1993, pp 57-58. At normal sky background it gives a limiting magnitude about $0^{\mathrm{m}} 8$ better than ZU21, and its astrometric qualities are also better. The NT-1A works well in light pollution, the Carte du Ciel astrographs at Pulkova and Tachkent showing limiting (B) magnitude of about 16.

During the winter of $1992-3$, NT-1A on $1.7 \mathrm{~mm}$ glass $(2.6 \mathrm{~mm}$ is also available) was tested at the $80 \mathrm{~cm}$ Schmidt camera near Riga in Lithuania. The $24 \times 24 \mathrm{~cm}$ plates were successfully bent mechanically for a focal length of $240 \mathrm{~cm}$. They show a better limiting magnitude and a more detailed picture of dark nebulae in $M 31$, due perhaps to better granularity and acutance of the new emulsion, not yet measurable during our laboratory sensitometry. 


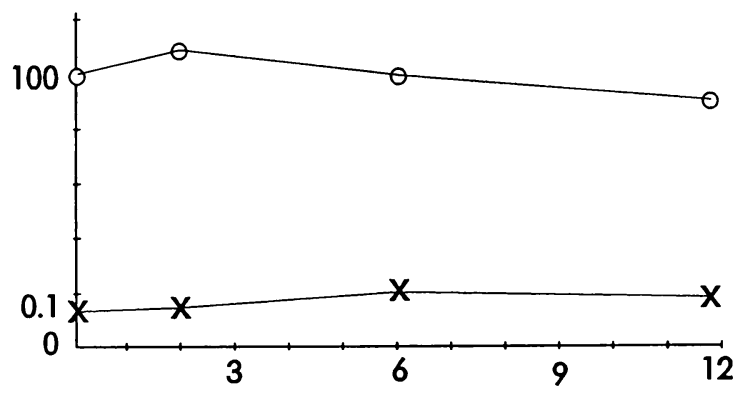

Figure 2.

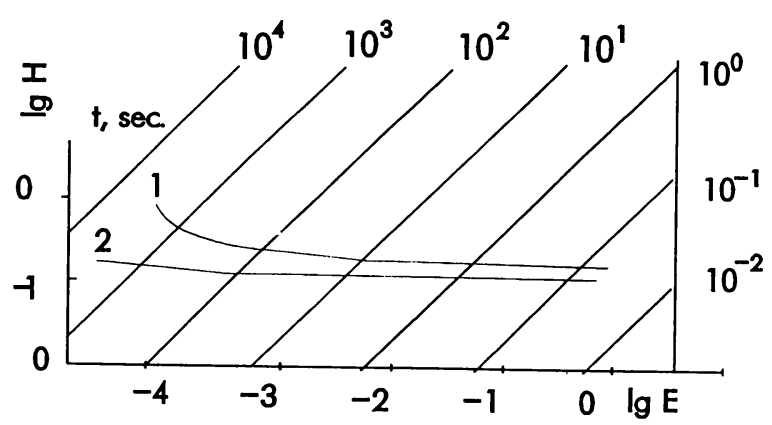

Figure 3.

\section{References}

Janusonis, G.A., 1978. 'Sensitization of photographic film in elevated-temperature hydrogen gas and its development', part I. Photographic Science and Engineering, vol. 22, N6, p. 297. Tschernyavsky, M.I., Worob'ewa, E.F., Kuzmitchewa, M.F. and Tret'yakowa, M.I., 1962. 'Izutchenije yadernich vzaimodejstwij wysokoj energii na wodorode', in 'Yadernaja fotografija', Moskwa, Izd.AN SSSR, p. 210. 